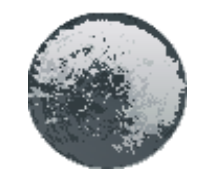

\title{
LEARNING SITUATIONS AND ICT SKILLS IN MATHEMATICS IN THE FIRST YEAR OF THE SECONDARY SCHOOL FOR ECONOMICS
}

\author{
Darinka Žižek \\ Secondary School of Economics Maribor, Slovenia
}

\begin{abstract}
This research presents one of many possibilities of how to check and repeat knowledge at the end of the school year and at the same time provide an answer to questions often asked by students who are disinterested in learning mathematics: "Where will we need it?" or "Why do we learn this?" To provide them with an answer and motivate them at the same time, this research focused on actively encouraging students to find the answers themselves and thus find the importance of learning mathematics. With a changed way of repeating and consolidating the material at the end of the school year, the aim of this research is to reduce the fear of mathematics and increase the motivation of students in the following year. Students, divided into groups, choose the topic or examples of the use of mathematical knowledge of the first year of secondary technical and professional education in everyday life, and thus shape the learning situation (LS). The goal of preparing the LS is for students to make sense of the subject matter with examples from everyday life. For the selected $L S$, they prepare a short story with tasks that they solve by calculation, prepare presentations and also, present the LS to the classmates.

During the formation of the LS and the preparation of presentations, students are active (active learning methods: task search, knowledge of the subject matter, interviews, problem solving, use of mathematical applications, teamwork, problem solving...) and cooperate with each other. They are constantly developing more 21st century competencies (self-regulation, collaboration, problem solving) and digital competencies. With the formation of the $L S$, the world of mathematical knowledge gets a little closer to students, they lose their fear of mathematics and become more motivated.
\end{abstract}

Keywords: learning situations, collaborative work, active learning methods, mathematics in everyday life, deviation from the established

\section{Introduction}

Because STEM subjects (science, technology, engineering, and mathematics) are perceived negatively, as being dry and boring (Joyce \& Dzoga, 2012), this research focused on planning a different manner in which students can work at the end of the school year. For the students uninterested in learning mathematics, this research attempted to provide an answer to their questions: "Where are we going to need this?" or "Why do we learn this?" One of the aims of this research is also for the students to transparently repeat and consolidate the material that is covered in the first year of secondary technical and vocational education. The last hours before the holidays in any subject are mostly boring for the students anyway. Grades are obtained and students no longer care about anything unrelated to the grade. Therefore, in mathematics, the work in the first year is finished in a slightly different way. Students are actively encouraged to find the meaning of learning mathematics on their own and find answers to their own questions.

In doing so, they should use all available ICT technology, mathematical applications that they learn to use during the school year, also because, according to Aberšek and Kordigel Aberšek (2011), ICT will play an important role in education. The aim of this 
research is to achieve a reduction in fear of math and increase student motivation in the coming year. The aim of the preparation of the LS is to make sense of the first-year teaching material with examples from everyday life and thus understand the importance of learning mathematics

With a different approach to the end of the school year, the aim of this research is to achieve the following:

- Students better understand the importance of learning math

- Learning situations reduce the fear of math

- Learning situations increase students' motivation to learn mathematical concepts.

Learning situations require thorough planning and consideration. When planning a learning situation, if it is to be carried out as well as possible with the most optimal didactic effects, the teacher or in particular, the teaching team should specifically identify the following key curricular components:

- $\quad$ phased (general and operational) goals that students will achieve in the learning situation and knowledge standards that will be the basis for assessing knowledge,

- $\quad$ learning content that will be the subject of discussion in the learning situation,

- description of the concept of didactic implementation of the learning situation,

- the structural sequence of content units that will form the learning situation, and

- $\quad$ material (especially spatial and didactic) conditions for quality and safe implementation of the learning situation (Skubic Ermenc et al., 2012, pp. 22)

\section{Presentation of the Work Process}

The entire teaching staff of the selected department were acquainted with the concept of the learning situation (LS), and were invited to participate. At the end of May, i.e., a few weeks before the end of the school year, students were introduced to a different approach from the regular transparent repetition and consolidation of learning material in mathematics. They were given instructions for choosing a topic or examples of using mathematical knowledge in everyday life or in an interdisciplinary connection, called the learning situation (LS). When choosing the LS, students had to use the material of the first year of secondary technical and professional education. The goal of the LS preparation was for students to make sense of the first-year subject matter, answer their questions, be active and learn about a different way of working. Furthermore, the Catalog of Knowledge in the chapter Forms of Verification and Assessment proposes mathematical research and project tasks (MIZŠ, 2007, pp. 42) with examples from everyday life. In this way, students were brought closer and were able to make sense of the importance of learning mathematics.

At first, students became acquainted with the working methods and the criteria according to which grades are formed. Students were able to independently choose topics that they either cross-curricularly connect or look for examples in everyday life. 


\section{Figure 1}

Graphic Display of Learning Situation

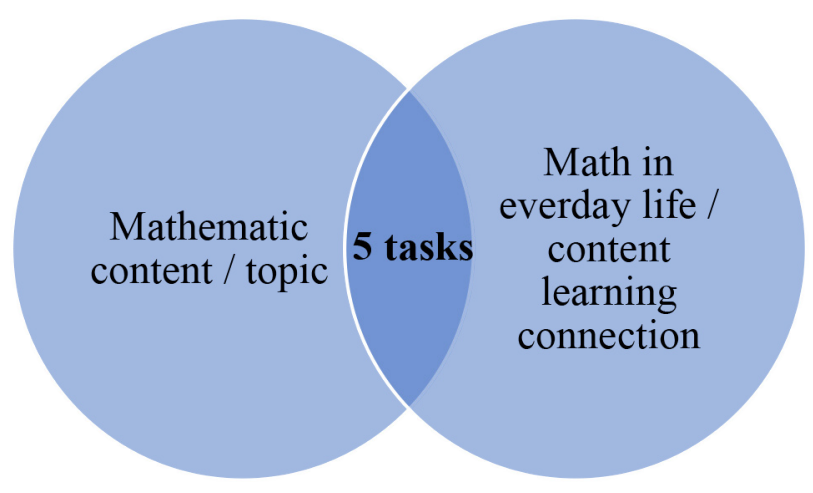

Students were offered a choice between thirteen math topics, which are to be covered in the first year. Use:

- natural and integers and relevant rules (counting, height difference, temperature, shopping in the store, spending of saved money, criteria of divisibility, basic theorem on division, ...)

- $\quad$ potency with natural exponents (e.g., notation of large numbers with power)

- fractions (graphic presentation, calculation with them, ...)

- $\quad$ powers with integer exponents (record of small numbers with power, decimal numbers, periodic decimal numbers, ...)

- expressions (calculating with them e.g., addition, subtraction, multiplication, square of a binomial, difference of squares, cube of a binomial, difference / sum of cubes, disassembly, Viet rule, quadruples, exposures of a common multiple)

- algebraic fractions and calculation with them (addition, subtraction, multiplication, and division)

- $\quad$ equations (linear, split, rational, equations with absolute value and irrational, use of equations e.g., in chemistry and elsewhere...)

- linear inequations

- real numbers (square and cubic roots, roots of higher degrees, intervals, absolute value)

- $\quad$ potency with rational exponents and connection with roots

- $\quad$ conclusive calculus (direct and inverse ratio)

- $\quad$ percentages and per mille

- $\quad$ systems of two equations with two unknowns.

Students were also introduced to the LS grading criteria. The following criteria were considered:

- Use at least five different mathematical concepts

- Use of appropriate mathematical terminology

- Link to everyday life or to a subject

- Correct solution of the selected task

- $\quad$ Proper language and form structure

- Use of ICT technology 
- Sovereign presentation of the learning situation

- $\quad$ Adherence to deadlines

Students are sorted into groups of their choice. In groups, they choose the topic and title of the LS. It is recommended that they may also include topics from other firstyear subjects related to mathematical skills. The selected topic must cover five different tasks from the offered or discussed topics of the mentioned program. Students notify the professor of the topic and the LS title by email. Each individual of the group prepares the task and its solution. Everyone in the group gets acquainted with individual tasks and checks the solutions. Before they start finalizing the LS, they need to present the LS concept to the professor.

The chosen titles can be e.g., next: School Lunch, Orchard, World War I, School Challenges, Travel and Vehicle Sales. The US contains a story (a record in one or two sentences) that includes 5 tasks with solutions.

Throughout the process of designing the LS, the work progress was monitored by checking the selection of tasks and solutions to tasks, advising or helping with technical difficulties, approving the presentation and also solving technical problems. For the selected LS, students prepare the tasks they searched for online, in textbooks Vega 1, i-textbooks (Mohorčič et al., 2014) and, of course, in their notebooks. The tasks must be solved by calculation, for which they can use various mathematical applications such as: Symbolab (EqsQest, 2017), Wolframalpha(Wolfram, 2020), That Quiz (That Quiz, undated). The work progress and the correctness of task calculations was monitored. Only after reviewing the selected tasks that must be sent by e-mail, the preparation of a presentation was approved, which had to include the use of information and communication technology. Presentations were presented to their classmates and teachers who are interested in the presentation.

To prepare the LS and make a presentation, students are given 5 hours. Some, especially those with a weaker knowledge in mathematics, need more guidance, help and guidance from both their classmates and the professor. If necessary, they can also supplement the work at home. They also work two hours in a computer classroom to prepare the presentation. They can design the presentation on their own. It must include a LS title, a short story (at least one sentence), 5 tasks and the solution of these. For the last hour, students present their LS in groups to other classmates and visiting teachers.

\section{Figure 2}

Structure of School Work

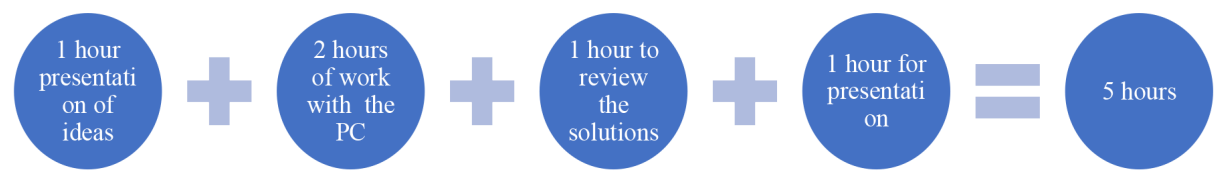

During the design of the LS and the preparation of presentations, students use active learning methods such as: finding a topic and suitable assignments, interviews, solving assignments, using mathematical applications, teamwork, learning from each other, problem solving and per-to-per collaboration. It is essential, however, that they demonstrate knowledge of the subject matter of the first year of secondary technical and 


\section{Exercise 4} In geography, we were given a very interesting takk of calculating the greatest common divisor and the least

- Morbor is a $5^{2}$ awoy from Ljbubljana, meoning $125 \mathrm{~km}$.

- Koper is a $3^{5}$ awoy from Morbor, meaning $243 \mathrm{~km}$.

Lublana is a $2^{7}$ away from kope, meaning $128 \mathrm{~km}$

- Moridor is a $2^{6}$ away from Cele, meaning $64 \mathrm{~km}$.

- Pruj is a $3^{5}$ away from fron meaning $243 \mathrm{~km}$.

Commondivisor - specifies the smallest exponents:

D $[243,64,128,243,125]=3^{5} \cdot 2^{6}$

- Common Multiple- Determine the common to the largest exponent like all the others:

o $v(234,64,128,243,125)=3^{5} \cdot 2^{\top} \cdot 5^{3}$

\section{Results}

The LS design met all expectations. The students were serious and enthusiastic in their pioneering work. Every student made an effort and contributed their share to the completed task. They showed interest in finding tasks and in cooperating with each other. Intense thinking about where to find the LS and how to present it connects students, reveals their abilities, and drives away the fear of math. In the interview after the activity, they reported that after their done work they understand the importance of learning mathematics and that they are less afraid of mathematics. This confirms the hypothesis that students, by creating LS, understand the importance of learning mathematics. In the school year following the learning situation, a greater level of motivation was observed, at least from the point of view that there are no more questions that are mentioned as an occasion and encouragement for a different approach.

With the preparation of the LS, students are forced to repeat the processed material and understand the importance of the learning material and its use in everyday life. During the work itself, they face relaxation, free choice of tasks in the LS, mutual cooperation, as well as problems such as finding suitable tasks that cover the processed material of the first year or the appropriate use of ICT. The role of the professor is primarily advisory and guiding.

Students use the time just before the holidays so actively and usefully. They demonstrate their knowledge of mathematics in the applicability of mathematics in the LS. Classes are more relaxed. Each group has its own pace. During the work itself, mutual cooperation, assistance to classmates, transfer of knowledge to each other is strengthened, and above all, they experience the applicability of mathematical knowledge for practical purposes and strengthen the use of ICT. In the future, the professor's introduction to the LS title and topic would be replaced by a one in OneNote's Lecture Book, or Office 365 OneDrive Cloud, instead of by e-mail.

Experience during the time of distance learning has shown that the class students who had experienced the learning situation in the previous school year participated more easily and more effectively at a distance and performed authentic tasks more independently, with less teacher assistance. 


\section{Conclusions}

The LS is a different approach from the classical way of repeating and testing mathematical knowledge. Students are forced to become active, as they have to find information about the processed material, choose a LS topic, choose assignments, and solve them. They have to prepare and carry out a presentation that intertwines and connects their knowledge with other subjects of the first year. Such activities force them into a different rhythm and course than they are used to. Because of this, the last hours of class become more interesting and more relaxed. So, the design of the LS certainly brings mathematical knowledge closer to students, which this example also confirms. By preparing LS, students reduce their fear of math and increase motivation, which is reflected in the independent work of students in the next year. Students with interest seek and produce a knowledge test for a chosen topic in the second year (which could be the topic of any of the following discussions) without the fear they had at the beginning of the first year.

Consolidating the knowledge of mathematics by creating the LS certainly enriches the learning process. It allows students to express themselves, and to express themselves in a different manner than just by assessing knowledge in tests or oral assessment. LS allows everyone to succeed and there is no fear that those students who do not like mathematics will have problems with LS. Experience shows it is quite opposite. All students show an interest in the work. This research confirms that each student successfully and to the best of their ability contributes their share to the making of the LS, even those who otherwise remain in the background. Also, the time used is more utilized than usually, as when students just wait for the holidays. The LS is an appropriate end to the school year and so it could be in other years meaning the end of the study of the subject matter in mathematics. With such an approach, the school year ends in a completely different way. It is important that students are active and find meaning in the learning process and also the prescribed contents.

\section{References}

Aberšek, B., \& Kordigel Aberšek, M. (2011). Does intelligent e-learning tools need more pedagogical methodology or ICT. Problems of Education in the 21st Century, 37, 9-17. http://www. scientiasocialis.lt/pec/node/633

EqsQest. (2017). Symolab. https://www.symbolab.com/

Joyce, A., \& Dzoga, M. (2012, januar 1). Ingenious. Intel White Paper: Science, technology, engineering and mathematics education: Overcoming challenges in Europe. https:// www.researchgate.net/publication/284023476_Intel_White_Paper_Science_technology_ engineering_and_mathematics_education_-_overcoming_challenges_in_Europe

MIZŠ. (2007). Katalog znanja - matematika [Catalog of knowledge - mathematics]. http:// portal.mss.edus.si/msswww/programi2009/programi/drugi_del/Ssi/KZ-IK/KZ_MAT_ SSI_383_408.pdf

Mohorčič, A., Pustovrh, S., Škrlec, M., Kapus, H., Zmazek, V., Jericijo, O., \& Rauter Repija, I. Vega 1. i-učbenik za matematiko $v$ 1. letniku gimnazij [Vega 1st i-textbook for mathematics in the 1st year of high schools]. Slovenia. http://eucbeniki.sio.si/vega1/

Skubic Ermenc, K., Drobne, J., \& Štefanc, D. (2012). Učne situacije v poklicnem in strokovnem izobraževanju [Learning situations in vocational and professional education]. Center za poklicno izobraževanje. http://www.cpi.si/files/cpi/userfiles/Publikacije/zbornik_Ucnesituacije_WEB.pdf

That Quiz. https://www.thatquiz.org/s1/

Wolfram. (2020). https://www.wolframalpha.com/

https://doi.org/10.48127/gu-nse/21.18.55 
Received 08 April 2021; Accepted 15 June 2021

Cite as: Žižek, D. (2021). Learning situations and ICT skills in mathematics in the first year of the secondary school for economics. Gamtamokslinis ugdymas / Natural Science Education, 18(1), 55-62. https://doi.org/10.48127/gu-nse/21.18.55

\section{\begin{tabular}{ll}
\hline \\
\end{tabular} Darinka Žižek}

Teacher, Secondary School of Economics Maribor, Trg Borisa Kidriča 3, 2000 Maribor, Slovenia. E-mail: Darinka.zizek@ses-mb.si

Website: https://www.ses-mb.si/index.php/predstavi/organiziranost/645-zizek-darinka-prof 